\title{
Bioprotection of Spruce Logs Against Sapstain Using an Albino Strain of Ceratocystis resinifera
}

\author{
Chantal Morin, Philippe Tanguay, Colette Breuil, Dian-Qing Yang, and Louis Bernier
}

First and fifth authors: Centre de Recherche en Biologie Forestière, Université Laval, Cité Universitaire, Québec G1K 7P4, Canada; second and third authors: Department of Wood Science, University of British Columbia, 2424 Main Mall, Vancouver, British Columbia V6T 1Z4, Canada; and fourth author: Forintek Canada Corp., Eastern Laboratory, 319 rue Franquet Québec, Québec G1P 4R4, Canada. Accepted for publication 28 December 2005.

\begin{abstract}
Morin, C., Tanguay, P., Breuil, C. Yang, D.-Q., and Bernier, L. 2006. Bioprotection of spruce logs against sapstain using an albino strain of Ceratocystis resinifera. Phytopathology 96:526-533.

We recovered a spontaneous albino strain from ascospores of Ceratocystis resinifera, a sapstain fungus that grows deeply and rapidly in freshly felled conifer trees. This albino strain, named Kasper, was tested for its ability to prevent discoloration of spruce sapwood caused by wildtype sapstain fungi and compared with Cartapip 97, a commercially available biological control agent of sapstain in lodgepole pine and red pine logs. In a laboratory trial, Kasper reduced sapstain of white spruce logs as

much as $94.4 \%$ and was more efficient than Cartapip 97. In field trials conducted in an area north of Québec City, Kasper reduced sapstain of black spruce as much as $80 \%$. In three of four field trials, Kasper was significantly more efficient than Cartapip 97 in reducing sapstain development. The exception was encountered in a 2003 trial conducted in a sawmill yard where Kasper did not reduce sapstain. In a field trial conducted in western Canada, at Aleza Lake forest near Prince George, Kasper almost totally prevented the development of sapstain, even after 24 weeks. These results suggest albino strains derived from $C$. resinifera might be an additional source of potential biocontrol agents against sapstain.
\end{abstract}

Sapstain, also referred to as blue stain, is an important problem for Canadian forest industries and is increasing concern around the world (5). This problem is the result of the colonization of wood by fungi with dark pigmented hyphae such as species of Ophiostoma, Ceratocystis, and Leptographium (33). These fungi do not affect the structural properties of wood but since they alter its appearance, they nevertheless reduce its value and the marketability of wood products $(14,23,29,32,33)$. A survey conducted in three mills during 1998 by Forintek Canada Corp. revealed that sapstain induced financial losses as much as \$5 million per mill per year in Alberta alone. The best stain prevention strategy is the rapid processing of logs. In most Canadian sawmills, however, unprocessed logs are stored in yards from 1 to 6 months (8) and although kiln drying can prevent fungal growth, rewetting during transportation and storage may still provide conditions favorable to the development of sapstain fungi (27).

Chemical biocides such as sodium pentachlorophenate were used for decades, but increasing concern about their environmental toxicity led to the exclusion of these most efficient antisapstain products (5). Moreover, registered anti-sapstain products can only be applied on freshly sawn lumber. In Canada, there are currently no registered chemical products for the control of sapstain on freshly felled logs (31). Since colonization of wood by staining fungi may start from the moment the trees are felled (36) and substantial stain may develop after only 1 month $(10,39)$, anti-sapstain products should be applied immediately after trees are felled at the harvesting site (6). Thus, the development of environmentally compatible agents to prevent sapstain would be very beneficial to the wood industry.

The application of albino strains derived from sapstain fungi is a promising biological control strategy against sapstain of wood

Corresponding author: L. Bernier; E-mail address: Louis.bernier@rsvs.ulaval.ca

DOI: 10.1094/PHYTO-96-0526

(c) 2006 The American Phytopathological Society
$(13,24,38)$. In small-scale field trials, Behrendt et al. $(1,2)$ demonstrated that an albino strain of Ophiostoma piliferum, commercially available under the trade name Cartapip 97, reduced the colonization of red pine (Pinus resinosa) logs by wild-type pigmented sapstain fungi. Cartapip 97, which is usually used to eliminate pitch or wood extractives in pulping processes in paper mills (12), was recently granted temporary registration in Canada under the name Sylvanex to control sapstain on freshly felled lodgepole pine (Pinus contorta) and red pine logs (31). Morrell et al. (30), however, showed that Cartapip 97 was generally unable to protect freshly sawn lumber of Hem-fir and Douglas fir. These authors suggested that the ineffective protection of Hem-fir probably reflected the difficulty of protecting a species with thick sapwood. Besides, in other studies, O. piliferum, from which Cartapip 97 was developed, and other Ophiostoma species were found to invade principally the bark and superficial layer of the sapwood and did not colonize logs as deeply as some Ceratocystis species $(16,35)$. For example, in laboratory tests carried out on lodgepole pine billets, Ceratocystis resinifera Harrington \& Wingfield, formerly known as $C$. coerulescens type C (22), was found to grow longitudinally seven times faster than $O$. piliferum $(15,16)$. In order to be efficient, a bioprotectant against sapstain must be a fast-growing organism, able to compete against other microorganisms and must have the ability to rapidly capture and dominate a major portion of the sapwood for an extended time (17). Thus, an albino strain derived from $C$. resinifera, a fastgrowing species able to penetrate deep in the sapwood, could potentially prevent sapstain of logs more efficiently than $O$. piliferum. In a previous study, a nonpigmented isolate of $C$. adiposa was reported to protect southern yellow pine (Pinus spp.) chips and $3-\mathrm{cm}$ thick disks against the development of sapstain from natural inoculum (9). However, C. adiposa was not assessed for the protection of logs. Morever, C. adiposa is a pathogen of sugarcane $(7,25)$. Given its ecological niche, $C$. resinifera seems a more appropriate choice than $C$. adiposa for the development of a biological agent against sapstain in conifer logs. 
Therefore, the first objective of this study was to obtain a stable albino strain from $C$. resinifera and evaluate its potential to protect freshly felled logs from sapstain. The second objective was to compare the efficiency of the $C$. resinifera albino and Cartapip 97 in preventing sapstain under the same conditions. One laboratory trial and five field trials were conducted to achieve these objectives. One of the field trials was conducted in British Columbia (western Canada), whereas all other tests were conducted in Québec (eastern Canada).

\section{MATERIALS AND METHODS}

Isolation of Kasper, an albino strain from $C$. resinifera. Approximately 300 isolates of $C$. resinifera recovered from a Canada-wide survey (28) were crossed in petri plates containing $2 \%$ malt extract agar (MEA) (Oxoid, Nepean, Canada). Four isolates were disposed $3 \mathrm{~cm}$ apart on each petri plate. One month later, perithecia resulting from these crosses were collected and surface sterilized by sequential immersion in $2.5 \%$ sodium hypochlorite $(30 \mathrm{~s})$ and $50 \%$ ethanol (30 s), followed by three washes in sterile deionized water $\left(\mathrm{H}_{2} \mathrm{Od}\right)$. Four perithecia from the same cross were crushed with a disposable Kontes pellet pestle (VWR, Montréal, Canada) in a 1.5-ml microtube containing $100 \mu \mathrm{l}$ of sterile $\mathrm{H}_{2} \mathrm{Od}$ to release ascospores. A 1:10 dilution was prepared by adding $900 \mu \mathrm{l}$ of sterile $\mathrm{H}_{2} \mathrm{Od}$, and after mixing the dilution, $100 \mu \mathrm{l}$ of the suspension was spread onto a large petri plate $(15 \mathrm{~cm})$ containing MEA amended with $0.01 \%$ deoxycholic acid to inhibit the radial growth of colonies. Over 50,000 colonies were visually screened to detect presence of nonpigmented strains. One spontaneous albino mutant, named Kasper, was obtained. Genomic DNA of the albino strain and its putative parents was extracted and subjected to random amplified polymorphic DNA (RAPD) analysis as described by Gagné et al. (18).

Other fungi tested. Wild-type isolates of $C$. resinifera (MB432) and $O$. piliferum (AU121-3) were used in the laboratory trial to make up for the absence of natural inoculum. These isolates were also used in the first field trial conducted at Forêt Montmorency in Québec where the extent of the natural inoculum was not known. In the western field trial, only one wild-type isolate of $C$. resinifera (EL3-21) was inoculated. In other field trials, the inoculum for pigmented sapstain fungi was natural. $C$. resinifera isolates (MB432 and EL3-21) were collected in 2000 at Forêt Montmorency (Québec) and Edson (Alberta), respectively (28), whereas the O. piliferum isolate was collected in Big River (Saskatchewan) in 1998 (37). The albino O. piliferum mutant Cartapip 97 was obtained from AgraSol Inc. (Raleigh, NC).

Formulation and application of inoculum. Fungi used in the eastern trials were grown in $2 \%$ malt extract broth (MEB) (Oxoid, Nepean, Canada) liquid culture in shake 4-liter Erlenmeyer flasks at room temperature. Cultures were aerated with an aquarium pump through a $0.2-\mu \mathrm{m}$ filter to prevent contamination. After approximately 3 weeks, they were homogenized in a Waring blender and the concentration was measured $24 \mathrm{~h}$ after diluted samples of the blended suspension were spread onto MEA petri plates. The concentration of each culture was estimated from the mean number of colony forming units (CFU) of three petri plates. The same petri plates were used 3 days later to verify the purity of cultures that were stored at $4^{\circ} \mathrm{C}$ during these procedures. Then, a culture of each tested fungus was individually incorporated in a formulation to obtain a final concentration of $1 \times 10^{5} \mathrm{CFU} / \mathrm{ml}$. The formulation was a mixture of xanthane gum (5\%) (Sigma-Aldrich, Oakville, Canada), alginic acid (0.8\%) (Sigma-Aldrich), and sterile $\mathrm{H}_{2} \mathrm{Od}$. It had the consistency of a viscous paste in order to ensure adherence of inoculum to each end of stacked logs and to preserve humidity of inoculum. For some trials, a sterile formulation without any fungus was used as a control.

Wheat grains (spring hard) served as formulation for $C$. resinifera isolates (EL3-21 and Kasper) used in the western trial. Wheat grains were first soaked in water overnight and then strained to remove excess water. Yeast extract $(20 \%)$ was mixed with grains prior to autoclaving for $30 \mathrm{~min}$. A 7-day-old fungal culture grown on cellophane placed on a MEA plate was homogenized in $50 \mathrm{ml}$ of sterile distilled water before it was mixed with one liter of sterile wheat grains and incubated at room temperature for 17 days. The colonized grains were then blended with sterile water to form a thick paste that was applied to both ends of each treated log.

Trees were felled with a chainsaw and immediately inoculated, except for the laboratory trial in which logs were inoculated approximately 3 to 5 days after felling because they had to be carried to the Forintek Eastern Laboratory where the experiment was set up. In eastern field trials, logs were stacked to reproduce the conditions of operational logging, whereas in the western field trial, logs were just laid down on the ground. A thick layer ( 3 to $4 \mathrm{~mm}$ ) of the formulation was applied with a spatula to each end of logs except for the laboratory trial where standing up billets were inoculated only at the top end. When artificial inoculation of wild-type isolates was performed, inoculum was applied using the same procedure 2 weeks after inoculation of albino strains to let the latter initiate colonization of wood before logs were confronted to pigmented strains.

Laboratory trial. A laboratory test was conducted at the Forintek Eastern Laboratory in Québec City, Canada during the summer of 2003. White spruce (Picea glauca) billets of $60 \mathrm{~cm}$ in length were used. The test consisted of 16 treatments representing all combinations of four formulated fungi: albino mutants Kasper and Cartapip 97 and pigmented isolates $C$. resinifera MB432 and O. piliferum AU121-3 (Table 1). All treatments were repeated three times and the 48 logs used as experimental units were stored in an incubator at $20^{\circ} \mathrm{C}$ during 12 weeks.

Field trials. In mid-May 2002, 100-year-old white spruce trees were felled at the Aleza Lake research forest in Prince George, British Columbia. The trees were cut into 3-m long sections. Three treatments were applied which consisted of (i) a noninoculated control; (ii) Kasper; and (iii) wild-type C. resinifera EL3-21. Treatments were distributed in randomized blocks and were reproduced six times. One-half of the treated logs were left in the forest for 10 weeks and the other half were left for 24 weeks.

In mid-August 2003, a test was set up at the Université Laval experimental forest (Forêt Montmorency) $100 \mathrm{~km}$ north of Québec City. Black spruce (Picea mariana) trees approximately 50 years

TABLE 1. Treatments representing all combinations of four formulated sapstain fungi used in a laboratory trial to evaluate and compare the potential of isolates of Ceratocystis resinifera (Kasper) and Ophiostoma piliferum (Cartapip 97) in preventing sapstain in spruce logs

\begin{tabular}{lcccc}
\hline & \multicolumn{5}{c}{ Fungi tested $^{\mathrm{a}}$} \\
\cline { 2 - 5 } Treatments & Kasper & Cartapip 97 & C. $r$. MB432 & O.p. AU121-3 \\
\hline 1 & - & - & - & - \\
2 & + & - & - & - \\
3 & - & + & - & - \\
4 & - & - & + & - \\
5 & - & - & - & + \\
6 & - & - & + & + \\
7 & + & - & + & - \\
8 & + & - & - & + \\
9 & + & - & + & + \\
10 & - & + & + & + \\
11 & - & + & - & + \\
12 & - & + & + & - \\
13 & + & + & + & - \\
14 & + & + & - & + \\
15 & + & + & + & + \\
16 & + & + & + & + \\
\hline
\end{tabular}

${ }^{\text {a }}$ Kasper $=$ an albino strain of $C$. resinifera ; Cartapip $97=$ an albino strain of $O$. piliferum; $C . r . \mathrm{MB} 432=$ a wild-type isolate of $C$. resinifera; and $O . p$. AU1213 = a wild-type isolate of $O$. piliferum. Wild-type isolates were inoculated 2 weeks after the albino isolates. $-=$ Uninoculated and $+=$ inoculated. 
old were cut into $120-\mathrm{cm}$ long logs. The experimental design was similar to the one used at the Forintek trial except that the four treatments combining the two albino strains were deleted (the last four treatments in Table 1). Thus, 36 logs were subjected to 3 repetitions of 12 treatments and stacked in the shade for 10 weeks.

In subsequent eastern trials, fewer treatments were tested while more repetitions were added in order to increase the power of statistical comparisons. In late August 2003, 50-year-old black spruce trees were cut into $240-\mathrm{cm}$ long logs and inoculated at the Forêt Montmorency site. Five treatments were applied: (i) a noninoculated control; (ii) a sterile formulation; (iii) Kasper; (iv) Cartapip 97; and (v) a combination of both albino strains. Treatments were reproduced five times and completely randomly distributed. One week later, the logs were carried out to the Leduc sawmill in St-Émile, $20 \mathrm{~km}$ north of Québec City. Treated logs were stacked in the yard for 10 weeks, approximately $5 \mathrm{~m}$ from logs used by the mill.

In mid-July 2004, 50-year-old black spruce trees were cut into $120-\mathrm{cm}$ long logs and inoculated at the Forêt Montmorency site. The experimental design was six randomized blocks of four treatments which consisted of (i) a noninoculated control; (ii) a sterile formulation; (iii) Kasper; and (iv) Cartapip 97. Blocks were distributed in rows from the ground up to determine if the position of logs influenced sapstain development. Treated logs were stacked in the shade for 13 weeks.

The last field trial was established in late July 2004, when 50 -year-old black spruce trees were cut in $120-\mathrm{cm}$ long logs and inoculated at the Forêt Montmorency site before they were carried out 1 week later to the Leduc sawmill. The experimental design was eight randomized blocks of six treatments: (i) a noninoculated control; (ii) a sterile formulation; (iii) Kasper; (iv) Cartapip 97; (v) a sterile formulation amended with sodium bicarbonate; and (vi) Kasper amended with sodium bicarbonate. The sterile formulation and the Kasper treatments were repeated twice in each block. The diameter of the logs $(10$ to $20 \mathrm{~cm})$ was similar within each block but differed between blocks. Treated logs were stacked in the mill yard for 13 weeks.

Reisolation of fungi and measurement of sapstain. Upon completion of the eastern trials, logs were brought back to Laval University where they were cut with a chainsaw into $10-\mathrm{cm}$ sections. The resulting wood disks were stored at $4{ }^{\circ} \mathrm{C}$ until fungal isolation and sapstain measurements were performed. Only the upper face of the disks marked during log sawing was used for these procedures. For each disk, the disk circumference and each stain spot were traced on transparent paper. The intensity of each stain spot was visually evaluated using a 1 to 5 scale with 1 indicating the lightest intensity of stain and 5 indicating the darkest stain. Immediately after tracing the contours of stain spots, disks were processed for isolation of the inoculated sapstain fungi to evaluate the extent of their growth. Depending on the experiment, 25 to $100 \%$ of disks were used for isolation. Four small (2-mm) pieces of wood were aseptically collected from each selected disk and transferred onto petri plates containing MEA amended with $0.01 \%$ copper sulfate $\left(\mathrm{CuSO}_{4}\right)$ to inhibit yeast growth (28). After incubation for 2 days at room temperature, petri plates were checked daily and any mycelium resembling the mycelium of Kasper, Cartapip 97, or other sapstain fungi was transferred onto a sterile MEA petri plate. Sapstain fungi were then identified morphologically.

After tracing papers were digitized with an hp scanjet $4470 \mathrm{c}$ scanner, the area of each disk and each stain spot was measured using the UTHSCSA Image Tool software (version 3.00; C. D. Wilcox, S. B. Dove, W. D. McDavid, and D. B. Greer, Texas University, San Antonio). Area and intensity of stain spot data were compiled and sapstain (blue) for each disk was calculated as follows:

Blue $=\operatorname{sum}_{i \text { to } x}\left\{A_{i} *\left[1+\left(0.1 * S_{i}\right)\right]\right\} / \mathrm{D}$ in which $A_{i}=$ area $\left(\mathrm{cm}^{2}\right)$ of the $i$ th stain spot on the upper face of the disk; $S_{i}=$ stain intensity ( 1 to 5 ) of the $i$ th stain spot; and D = disk area $\left(\mathrm{cm}^{2}\right)$.

The intensity was multiplied by 0.1 to assign a lower weight to this variable which was visually evaluated. Then, the mean of 'blue' per disk was calculated for each log and used for statistical analysis.

In the western trial, three $\operatorname{logs}$ per treatment were sampled 10 and 24 weeks after inoculation. A $10-\mathrm{cm}$ disk from each end was first cut with a chainsaw to remove any remaining wheat grain and molds, and then, $5-\mathrm{cm}$ thick disks were taken every $50 \mathrm{~cm}$ along the length of each log. The area of traced stain spots was evaluated using a $1-\times 1-\mathrm{cm}$ grid transparency, and the percentage of sapstain was calculated for each disk. The cleaned disks were wrapped in newspaper and stored at room temperature for 2 days. Eight small (2-mm) wood samples were taken from each disk and transferred onto petri plates containing MEA amended with ampicillin $(0.005 \%)$. After incubation at room temperature for 3 days, any sample containing fungal growth was transferred onto sterile MEA plates. These isolates were then examined morphologically after 1 week for species identification.

Statistical analyses. The two variables measured (blue and percent sapstain) were subjected to an analysis of variance (ANOVA) relevant to the experimental design. For the western trial, time was also used as variable in the ANOVA. Logs were considered as the experimental unit. Before analyses, the variable blue was transformed to arcsine of the square root to satisfy the criteria of homogeneity of variances and normality based on graphical analysis of residuals. The nontransformed means are reported. In the second season of field trials, we increased the number of repetitions because of the high data variability observed in the first season, especially in untreated logs since some of these logs were exempt of sapstain, whereas others were highly stained by natural inoculum. To detect differences among treatments in spite of high data variability, we used contrasts that are highly powerful comparison tests. Thus, if treatments were significantly different $(P<0.05)$, a priori contrasts were used to compare means of control (uninoculated) treatment and treatments in which Kasper and Cartapip 97 were inoculated, and to compare Kasper and Cartapip 97 treatments against each other. For the sawmill trial conducted in 2004, sterile formulation treatments were also compared with Kasper treatments. Statistical analyses were performed using SAS computer programs (SAS Institute Inc., Cary, NC).

\section{RESULTS}

Recovery of a $C$. resinifera albino mutant. Crosses performed among wild isolates of $C$. resinifera generated four progeny isolates with an unstable pale color phenotype and only one isolate without any pigmentation (Fig. 1A and B). The latter, named Kasper, was recovered from a cross between isolates PB632 and SB342 from Plaster Rock (New Brunswick) and St-Émile (Québec), respectively. Six genetic markers obtained with four RAPD primers (OPA9, OPA10, OPQ1, OPP12) were polymorphic between isolates PB632 and SB342. Amplification of Kasper genomic DNA with these four primers showed the same six alleles observed in PB632. The albino phenotype of Kasper was found to be mitotically stable over 5 months of growth in conifer logs.

Laboratory assessment of Kasper against sapstain. In controlled laboratory conditions, logs inoculated with pigmented isolates and treated with Kasper showed significantly less sapstain (blue) than the untreated logs $(P<0.0001)$ (Fig. 2). When $\operatorname{logs}$ were inoculated with the pigmented isolate $O$. piliferum AU121-3, treatment with Kasper reduced sapstain by more than twofold, although the difference was not significant $(P=$ 0.1413) (Fig. 2). A missing value for the pigmented $O$. piliferum 
treatment (control) may explain why the statistical test did not detect a difference between the treatments. Nevertheless, Kasper and Cartapip 97 were less efficient in reducing sapstain development caused by $O$. piliferum than sapstain caused by $C$. resinifera. Kasper reduced sapstain caused by $C$. resinifera significantly more than Cartapip 97, $(P=0.0114)$ (Fig. 3). For the other cases, the difference was not significant. The reduction of sapstain varied from 64.6 to $94.4 \%$ with the Kasper treatment and from 22.3 to $79.0 \%$ with the Cartapip 97 treatment. Logs treated with both albinos showed similar percentages of sapstain reduction (64.9 to $98.5 \%$ ) as those treated with Kasper alone.

Assessment of Kasper against sapstain under field conditions. In the western trial, Kasper almost totally prevented the development of sapstain caused by natural inoculum, even after 24 weeks (Fig. 4A). Logs treated with Kasper had 99.0\% less sapstain than untreated logs after 24 weeks $(P<0.0001)$. Sapstain

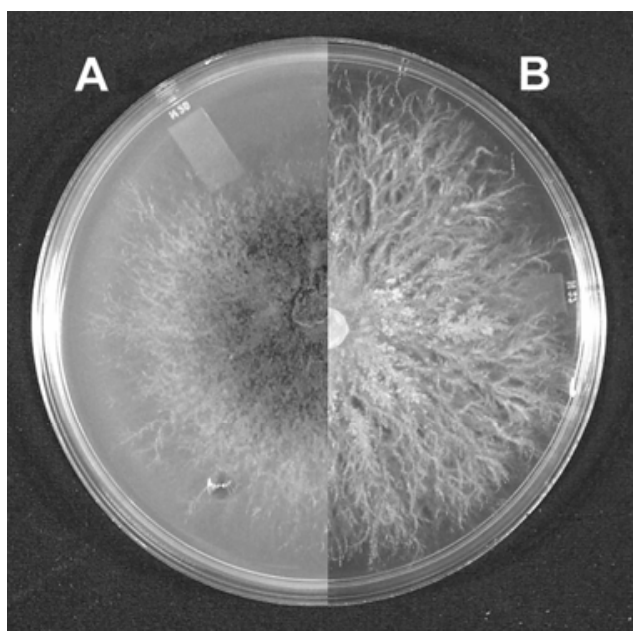

Fig. 1. A, The wild-type isolate of Ceratocystis resinifera MB432. B, The albino isolate of $C$. resinifera, named Kasper, recovered from a cross between isolates PB632 and SB342 from Plaster Rock (New Brunswick) and St-Émile (Québec), respectively.

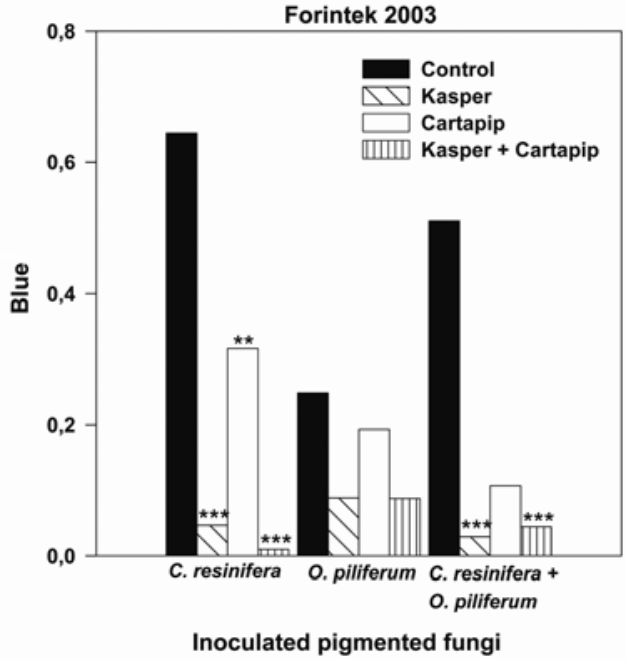

Fig. 2. Sapstain development in white spruce logs treated with Kasper and Cartapip 97, alone or in combination, and inoculated with different sapstain fungi in the 2003 Forintek laboratory trial. Asterisks over the bars indicate that the treatment is significantly different from control for the same inoculated pigmented fungus or fungi $(* *=P \leq 0.01, * * *=P \leq 0.001)$. Blue $=$ sum of areas of sapstain spots per disk $(1+$ (intensity $\times 0.1) /$ disk area $)$. Intensity of each sapstain spot was evaluated visually on a 1 to 5 scale. Each value represents the mean of 'blue' for three logs and the value per log was obtained by the mean of 'blue' for six disks.

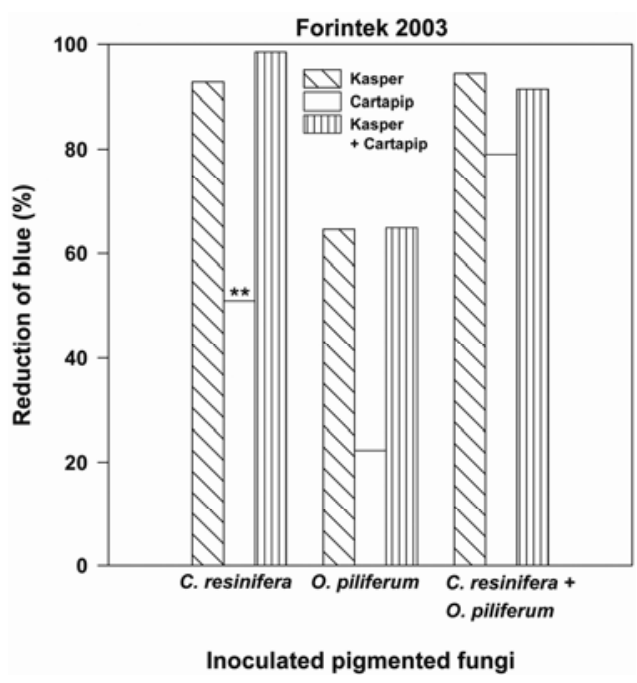

Fig. 3. Mean percentage of reduction of sapstain (blue) in white spruce logs treated with Kasper and Cartapip 97, alone or in combination, in the 2003 Forintek laboratory trial. Asterisks over the bar indicate that the treatment is significantly different from the Kasper treatment for the same inoculated pigmented fungus or fungi $(P \leq 0.01)$. Each value represents the mean of percentage of reduction for three logs.

A

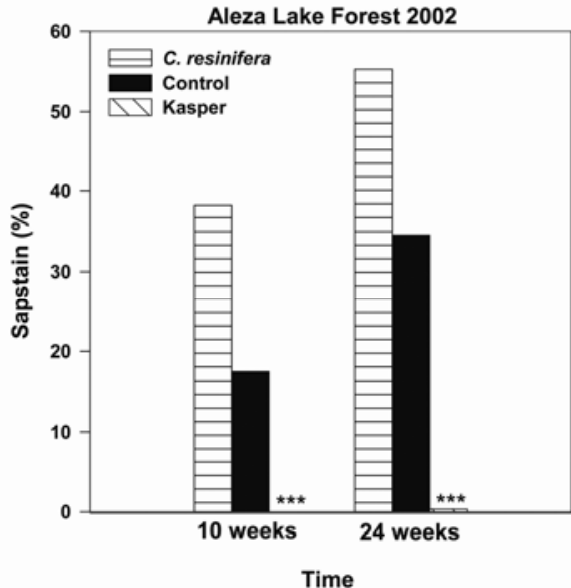

B

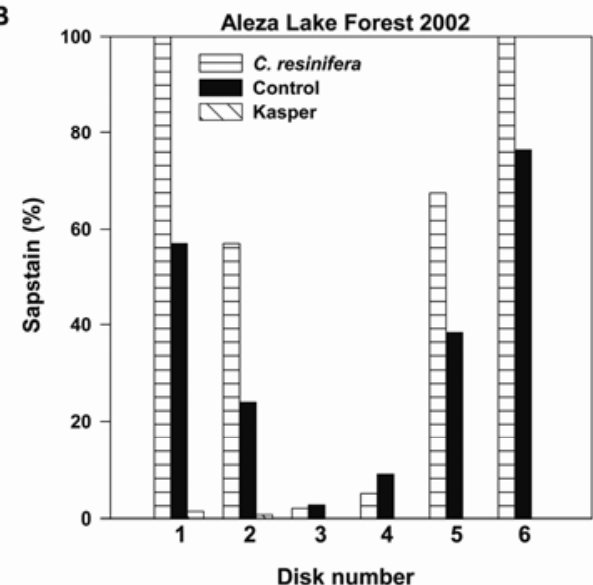

Fig. 4. A, Sapstain development in white spruce logs treated with Kasper after 10 and 24 weeks in the Aleza Lake Forest trial (British Columbia) in 2002. B, Percentage of disk surface affected by sapstain. Each value is the mean of disks from three logs. Wild-type isolate EL3-21 was used in the Ceratocystis resinifera treatment. Six disks (1 to 6) were cut at distances of $15,70,125$, 180, 235, and $290 \mathrm{~cm}$ along the length of 3-m long logs. Asterisks over the bars indicate that the treatment is significantly different from the control $(P \leq 0.001)$. 
development followed a negative gradient from ends to the middle of logs (Fig. 4B).

In eastern trials, logs developed less sapstain than in the laboratory trial or in the western field trial. Kasper inhibited sapstain development (Fig. 5A and B) more efficiently at the forest site than at the Leduc sawmill yard. The extent of sapstain development was, however, generally lower in the forest than in the sawmill (Fig. 6A, B, C, and D). Consequently, the detection of significant differences between treatments was more limited for the forest site. Nevertheless, logs treated with Kasper and inoculated with $C$. resinifera showed significantly less sapstain than control $\operatorname{logs}$ at the Forêt Montmorency in $2003(P=0.0508)$ (Fig. 6A). Inversely, Kasper did not reduce sapstain at the Leduc sawmill in 2003 (Fig. 6B). The level of sapstain was even higher on logs treated with Kasper, although the difference was not significant $(P=0.3006)$, and the general level of sapstain was relatively low compared with the following year (Fig. 6B and D). In 2004, Kasper significantly reduced colonization of sapstain fungi in logs stacked at the Leduc sawmill compared with control logs or $\log$ s treated with a sterile formulation (paste) $(P=0.0048$ and $P=$ 0.0205 , respectively) (Fig. 6D). In this field trial, the addition of sodium bicarbonate did not improve the efficiency of Kasper. Overall, Kasper reduced sapstain in all eastern field trials except for the sawmill trial conducted in 2003, and the reduction varied from 70.5 to $80 \%$ (Fig. 7). In these trials, Kasper controlled sapstain significantly better than Cartapip 97, which only provided from 0 to $33.0 \%$ of reduction in sapstain development. Cartapip 97 did not reduce sapstain development in the 2004 Forêt Montmorency trial.

Effect of log position and diameter on sapstain development. In the 2004 Forêt Montmorency field trial, randomized blocks were established to determine if the log position in the pile could affect sapstain development. On the basis of statistical analysis, blocks had no significant effect $(P=0.1741)$, thus log position did not seem to exert an influence on colonization of logs by sapstain fungi. Similarly, no block effect $(P=0.5153)$ was observed in the 2004 Leduc sawmill trial in which blocks were laid out according to log diameter, indicating that the diameter of logs, which varied from 10 to $20 \mathrm{~cm}$, did not affect sapstain development. In the two eastern trials conducted in 2004, the sterile formulation treatment showed a lower level of sapstain compared with the control, but a higher level than the Kasper treatment.
Isolation of inoculated fungi. Generally, inoculated fungi were reisolated from almost all treated logs except for the laboratory trial where logs showed a higher incidence of molds. Kasper was reisolated from only $28 \%$ of wood disks, but reisolated more frequently than Cartapip 97, which was reisolated from only $4 \%$ of disks. In the Forêt Montmorency trials, which showed higher rates of reisolation, the longitudinal growth of Cartapip 97 was estimated on the basis of the distance between the inoculation point at each end of the treated logs and the most distant disk where it was detected. Since the growth of Kasper from each end overlapped in the middle of the treated $120-\mathrm{cm}$ long logs in the Forêt Montmorency trials, its growth rate was evaluated for the Leduc sawmill trial conducted in 2003 where longer logs $(240 \mathrm{~cm})$ were used. The daily growth rate of Cartapip 97 in black spruce logs was estimated to be 0.3 to $0.4 \mathrm{~cm}$, approximately five to six times slower than the rate of $1.9 \mathrm{~cm}$ estimated for Kasper.

\section{DISCUSSION}

Over 50,000 colonies of $C$. resinifera had to be screened to recover one stable, spontaneous albino strain, which we named Kasper. This compares with the efforts by Zimmerman et al. (40) to obtain a white isolate of $O$. piliferum. The growth of Kasper in sapwood blocks was similar to the growth of wild-type isolates of C. resinifera (34) suggesting Kasper had potential as a wood protective agent. Attempts to cross Kasper with various wild-type isolates were unsuccessful, preventing us from verifying genetically if the albino phenotype was caused by a single gene change, as was the case for $O$. piliferum (40). However, we recently obtained molecular evidence that a single mutation in a melanin biosynthesis gene is responsible for the colorless phenotype of Kasper (34). Analysis of six RAPD markers in Kasper genomic DNA revealed that they were the same alleles as those found in the parent $C$. resinifera PB632, thus suggesting Kasper is a progeny from a PB632 self-fertilized perithecium. Harrington and McNew (21) previously reported that in Ceratocystis spp. found on conifers, MAT-2 strains were capable of selfing because of unidirectional mating type switching.

Kasper reduced sapstain development in spruce logs and did so more efficiently than Cartapip 97 in both laboratory and field trials, except for one trial conducted at the Leduc sawmill in 2003. Even in the field trials, reduction of sapstain was mostly

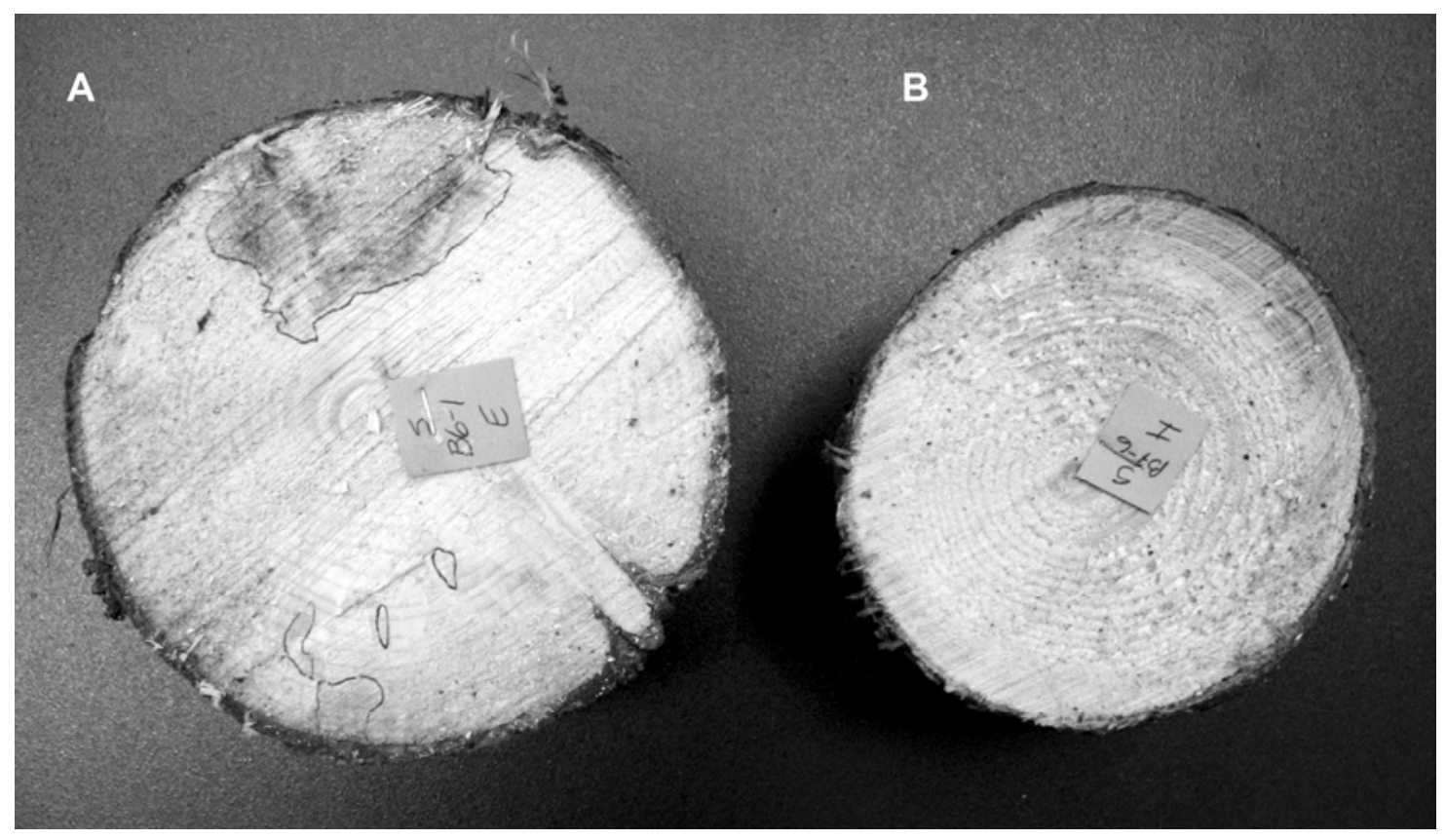

Fig. 5. A, Development of sapstain in untreated black spruce log. B, Black spruce log treated with Kasper at the Leduc Sawmill site in 2004. 
significant and reached $70 \%$ or more. Under controlled laboratory conditions, Kasper was very efficient in inhibiting colonization of $\operatorname{logs}$ by $C$. resinifera MB432, reducing sapstain development by 92.8\% compared with the control, but was slightly less efficient in reducing sapstain caused by $O$. piliferum AU121-3. However, the lower efficiency against $O$. piliferum was not observed in the 2003 Forêt Montmorency trial.

Treatment of logs with Kasper was more efficient in the western field trial (99\% sapstain reduction) than in the eastern field trials (no more than $80 \%$ reduction). Factors such as tree species, climatic conditions, or inoculation procedures might explain this variation. Because of differences in the distribution of conifer species at the experimental sites, two different species, white and black spruce, were used in the western and eastern field trials, respectively. Eventually, Kasper would have to be tested on every important North American conifer since susceptibility to sapstain varies among different wood species (33). Sapstain development can be also affected by moisture and temperature conditions $(19,33)$, which are probably critical for the rapid colonization of Kasper in logs following its inoculation. Mild temperatures are preferable since growth of $C$. resinifera is optimal at $20^{\circ} \mathrm{C}(22)$. Moreover, considering the role of melanin in protection against desiccation and ultraviolet rays in some fungi $(3,4)$, the albino phenotype is possibly more vulnerable to sunlight and desiccation than wild-type strains. Thus, hot sunny days at the beginning of eastern field trials, which were set up in mid-summer, might have been less favorable for the establishment of Kasper than moderate spring temperatures at the Aleza Lake site in western Canada. A shaded forest also provides milder temperatures than an open mill-yard where logs may be exposed to extreme climatic conditions. Moreover, in eastern field trials, the average level of colonization of logs by wild-type sapstain fungi was higher in a sawmill than in the forest in 2003 and 2004, suggesting that the natural inoculum might be more important in a sawmill than in a forest. This is in concordance with the lower recovery rate of Ceratocystis species at Forêt Montmorency than at sawmill sites during a survey conducted in the summer of 2000 . At the forest site, we obtained only one-fourth of the average number of isolates collected at eastern sawmill sites using the same isolation procedures. Additional samplings of other forest and sawmill sites would help verify whether natural inoculum is more concentrated in a sawmill than in forest sites. Nevertheless, our results suggest that in order to improve the efficacy of Kasper, logs should be kept in the forest at the harvesting site as long as possible. This would give Kasper a chance to colonize a large proportion of logs before it is exposed to harsher sawmill conditions and before additional bark damage sustained during transportation provides wildtype sapstain fungi with additional opportunities to invade logs.
A

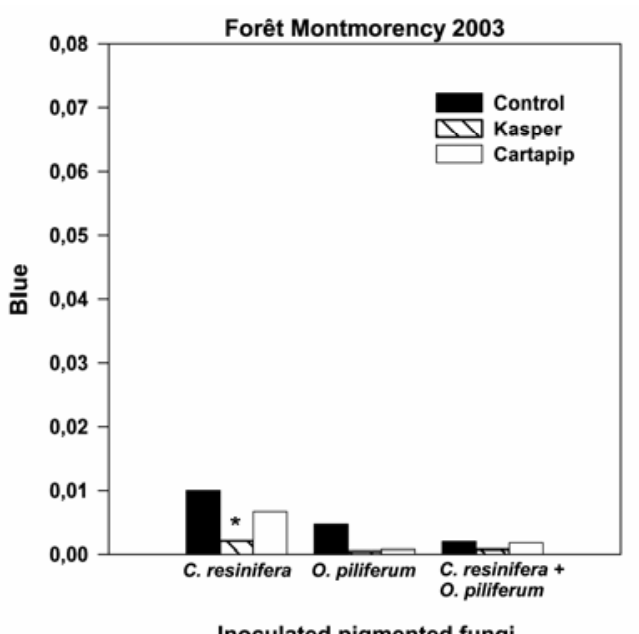

B

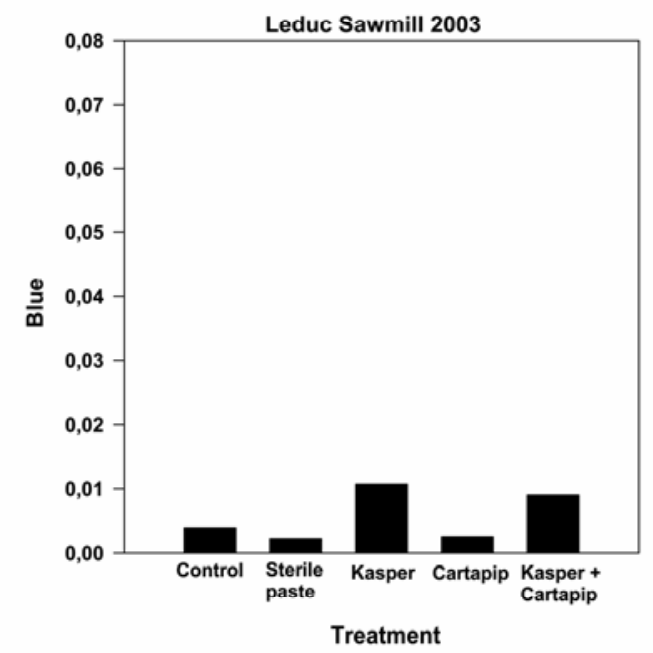

C

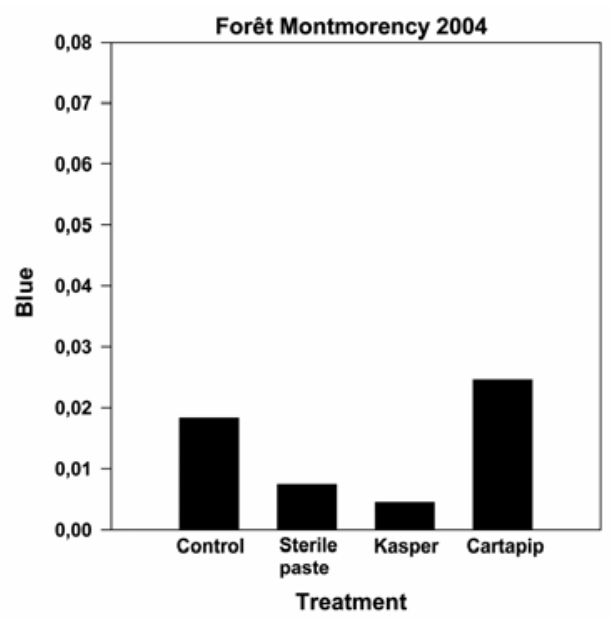

D

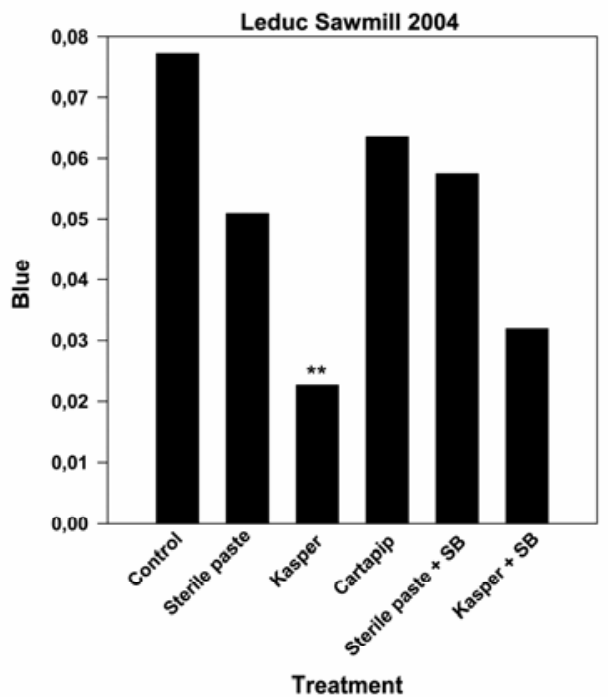

Fig. 6. A, Sapstain development in black spruce logs treated with Kasper or Cartapip 97 and inoculated with different sapstain fungi at the Forêt Montmorency in 2003. B, Sapstain development in black spruce logs treated with the sterile formulation (paste) and with Kasper and Cartapip 97, alone or in combination, at the Leduc sawmill in 2003; C, at the Forêt Montmorency in 2004; and D, at the Leduc sawmill in 2004. For all graphs, the asterisk over the bar indicates that the treatment is significantly different from the control $(*=P \leq 0.05, * *=P \leq 0.01)$. Blue $=$ sum of areas of sapstain spots per disk $(1+$ (intensity $\times 0.1) /$ disk area). Intensity of each sapstain spot was evaluated visually on a 1 to 5 scale. Each value represents the mean of several logs; the value of blue per log is the average from 12 or 25 disks depending on the trial. 
Inoculations along the logs could also help the establishment and success of Kasper. Under operational tree harvesting conditions, $\operatorname{logs}$ are left in the forest, sometimes as much as 2 weeks (Clément Aubin, Leduc Sawmill, personal communication). On the basis of our estimate that the daily growth of Kasper in spruce logs is approximately $1.9 \mathrm{~cm}$, standard 240-cm (8-foot) long logs should be inoculated at both ends and at five other evenly spaced locations along the logs to ensure that they are entirely colonized by Kasper within 2 weeks. Ideally, the inoculum should be applied to whole logs via the harvesting equipment. Since logging operations induce several wounds through the bark of logs (36), simultaneous application of the inoculum should allow the biocontrol agent to rapidly and fully colonize the sapwood.

In spite of the fact that formulation and application of Kasper were not optimized in this study, the results demonstrated that this albino mutant could inhibit more than $70 \%$ of saptain development on freshly felled spruce logs. Kasper failed to reduce discoloration only in the 2003 sawmill trial. Longer logs $(240 \mathrm{~cm})$ used in this trial could possibly explain the poor performance of Kasper. Without inoculum application on sides, a large portion of the log was not colonized and was thus very susceptible to stain by natural inoculum brought by insect vectors. Logs treated with Kasper may have been more attractive to insect vectors than untreated $\operatorname{logs}$, due to liberation of volatile metabolites by the fungus. Laboratory cultures of Kasper release fruity odors characteristic of Ceratocystis and Ophiostoma species (20) and, if this is also the case in vivo, this may explain the slightly higher level of sapstain in logs treated with Kasper. The hypothetical attraction of insects by Kasper, however, did not impede its performance in the other field trials.

The comparative assessment of Kasper and Cartapip 97 showed that the former had a superior potential to prevent spruce log colonization by sapstain fungi under the conditions used in the current study. Kasper was significantly more efficient than Cartapip 97 in all experiments except in the sawmill trial conducted in 2003 (Fig. 6B). Because of material constraints, we had to inoculate Kasper and Cartapip 97 at low concentrations, i.e., $1 \times$ $10^{5} \mathrm{CFU} / \mathrm{ml}$. In comparison, the final concentration of Cartapip 97 used in the commercial formulation Sylvanex is $5.0 \times$ $10^{7} \mathrm{CFU} / \mathrm{ml}$ (31). While Cartapip 97 might have prevented sapstain more efficiently when applied in higher concentration, a similar

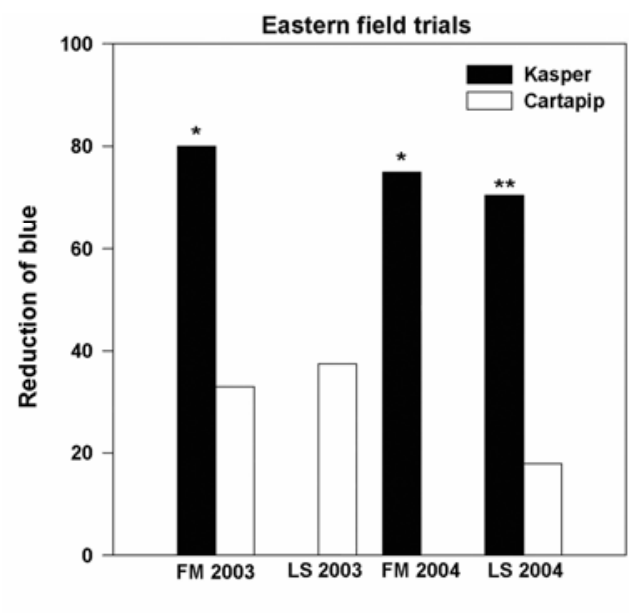

Trial

Fig. 7. Percentage of reduction of sapstain development (blue) on black spruce logs treated with Kasper or Cartapip 97 in field trials conducted in eastern Canada. FM = Forêt Montmorency and LS = Leduc sawmill. Asterisks over the bars indicate that Kasper treatment is different from Cartapip 97 treatment $(*=P \leq 0.05, * *=P \leq 0.01)$. Blue $=$ sum of areas of sapstain spots per disk $(1+$ (intensity $\times 0.1) /$ disk area). Intensity of each sapstain spot was evaluated visually on a 1 to 5 scale. Each value represents the mean of several logs; the value of blue per $\log$ is the average from 12 or 25 disks depending on the trial. argument could be made for Kasper. Nevertheless, treatment of logs with Kasper, even at a relatively low concentration, inhibited more than $70 \%$ of sapstain in most field experiments, whereas the highest reduction obtained with Cartapip 97 in these experiments was $37.5 \%$. The latter was granted registration (Sylvanex) to control sapstain in lodgepole pine and red pine logs in Canada. Possibly, Cartapip 97 might be more efficient on these tree species. We tested Cartapip 97 and Kasper on white and black spruce since these species were the ones that were readily available to us and could be treated immediately after they were felled. We estimated that Kasper grew five to six times more rapidly than Cartapip 97 in black spruce logs. A similar observation was reported for lodgepole pine logs $(15,16)$. This suggests that Kasper might also provide superior protection on pine logs. Moreover, since $O$. piliferum colonizes only the superficial layer of sapwood (16), the difference between the respective efficacy of Cartapip 97 and Kasper might be further accentuated in logs with higher proportion of sapwood, although further tests on various tree species are needed to establish the full extent of Kasper ability as a biocontrol agent against wood discoloration.

The advantage of the competition mechanism as a strategy for protection is that the biocontrol agent occupies the same niche as the organisms that it is supposed to control. In the current case, if environmental conditions favor sapstain fungi they should also affect the biocontrol agent in a relatively similar way. Since the latter is mass inoculated, it should be at an advantage over wildtype sapstain fungi. Inoculation of logs immediately after they are felled and before they are invaded by pigmented sapstain fungi is also a key to success for a competing biocontrol agent since the albino is not an antagonist and cannot displace other sapstain fungi. In this study, we did not test later inoculation of the albino strains since previous studies had demonstrated that this approach provided less efficient control $(1,26)$. Biological control of sapstain using different organisms such as bacteria or nonrelated fungi is often more complicated because environmental conditions can favor sapstain fungi to the detriment of the biocontrol agent. In a study comparing the efficacy of an albino strain of $O$. piliferum, Bacillus subtilis, and Gliocladium virens, the authors reported that $B$. subtilis and $G$. virens were apparently not suitable for reduction of sapstain. On the other hand, only $7 \%$ of discoloration occurred on Scots pine inoculated with the $O$. piliferum albino as opposed to $74 \%$ in uninoculated controls (11). Thus, using albino strains of sapstain fungi might be preferable as a control strategy. In the current study, Kasper, an albino strain of $C$. resinifera, reduced sapstain development more efficiently than the albino $O$. piliferum Cartapip 97 in spruce logs. These results justify further studies to optimize Kasper efficiency and evaluate abiotic factors that may influence its development on logs. In particular, some observations made in the course of this study suggest that inoculation of whole $\operatorname{logs}$, increased inoculum concentration, and longer incubation of inoculated logs in the forest before they are transferred to the mill are avenues worth investigating for improving the efficiency of Kasper. In addition, the interaction between $C$. resinifera and living trees needs to be documented in order to ensure the environmental innocuity of an anti-sapstain treatment based on the large scale application of an agent such as Kasper. We are thus investigating whether Kasper and wild-type strains of $C$. resinifera are pathogenic to living trees.

\section{ACKNOWLEDGMENTS}

Funding for this work was provided by a Natural Sciences and Engineering Research Council of Canada (NSERC) Strategic grant to L. Bernier and C. Breuil, and a NSERC Network Grant (Biocontrol Network). We wish to thank personnel at the participating mills, experimental forests, and Forintek Canada Corp.; É. Leclerc, É. St-Michel, G. Racine, M. Pouliot, and S. VanRietschoten for their help in the inoculation, isolation, and sawing of logs. 


\section{LITERATURE CITED}

1. Behrendt, C. J., Blanchette, R. A., and Farrell, R. L. 1995. Biological control of blue-stain fungi in wood. Phytopathology 85:92-97.

2. Behrendt, C. J., Blanchette, R. A., and Farrell, R. L. 1995. An integrated approach, using biological and chemical control, to prevent blue stain in pine logs. Can. J. Bot. 73:613-619.

3. Bell, A. A., and Wheeler, M. H. 1986. Biosynthesis and functions of fungal melanins. Annu. Rev. Phytopathol. 24:411-451.

4. Butler, M. J., and Day, A. W. 1998. Fungal melanins: A review. Can. J. Microbiol. 44:1115-1136.

5. Byrne, A. 1998. Chemical control of biological stain: Past, present, and future. Pages 63-69 in: Biology and Prevention of Sapstain. Forest Products Society, Madison, WI.

6. Byrne, A. 1999. Canadian research in sapstain control-brief history and current focus. Pages 81-85 in: The 2nd New Zealand Sapstain Symposium. B. Kreber, ed. Forest Research Institute, Rotorua, New Zealand

7. Byther, R. S. 1971. Black rot of sugarcane cuttings in Hawaii. Plant Dis. Rep. 55:7-9.

8. Clark, J. E. 1992. Fungal stain in Canadian softwood sawlogs. Report No. 35. Publ. 1712K005. Can. For. Serv. Ottawa, ON, Canada.

9. Croan, S. C. 1996. Biological control of sapstain fungi in wood. International Research Group on Wood Preservation. IRG/WP/96-10158, 10. IRG Secretariat, Stockholm, Sweden.

10. Davidson, R. W. 1935. Fungi causing stain in logs and lumber in the southern States, including five new species. J. Agric. Res. 50:789-807.

11. Ernst, E., Kehr, R., Muller, J., and Wulf, A. 2004. Chances for biological protection of conifer wood from bluestain. Moglichkeiten zum biologischen Schutz von Nadelholz vor Stamm- und Schnittholzblaue. Nachrbl. Dtsch. Pflanzenschutzd. 56(8):169-179.

12. Farrell, R. L., Blanchette, R. A., Brush, T. S., Hadar, Y., Iverson, S., Krisa, K., Wendler, P. A., and Zimmerman, W. 1993. Cartapip: A biopulping product for control of pitch and resin acid problems in pulp mills. J. Biotechnol. 30:115-122.

13. Farrell, R. L., Hadar, E., Kay, S. J., Blanchette, R. A., and Harrington, T. C. 1998. Survey of sapstain organisms in New Zealand and albino antisapstain fungi. Pages 57-62 in: Biology and Prevention of Sapstain. Forest Products Society Madison, WI.

14. Findlay, W. P. K. 1959. Sap-stain of timber. Part I. For. Abstr. 20(1):1-7.

15. Fleet, C. A. 2001. Growth, nutrition and genetic factors that affect pigmentation of wood-sapstain fungi. M.S. thesis. University of British Columbia, Vancouver, Canada.

16. Fleet, C. A., Breuil, C., and Uzunovic, A. 2001. Nutrient consumption and pigmentation of deep and surface colonizing sapstaining fungi in Pinus contorta. Holzforschung 55:340-346.

17. Freitag, M., Morrell, J. J., and Bruce, A. 1991. Biological protection of wood: Status and prospects. Biodeterioration Abstr. 5:1-13.

18. Gagné, P., Yang, D.-Q., Hamelin, R. C., and Bernier, L. 2001. Genetic variability of Canadian populations of the sapstain fungus Ophiostoma piceae. Phytopathology 91:369-376.

19. Gibbs, J. N. 1993. The biology of ophiostomatoid fungi causing sapstain in trees and freshly cut logs. Pages 153-160 in: Ceratocystis and Ophiostoma. Taxonomy, Ecology and Pathogenicity. M. J. Wingfield, K. A. Seifert, and J. F. Webber, eds. The American Phytopathological Society, St. Paul, MN.

20. Hanssen, H.-P. 1993. Volatile metabolites produced by species of Ophiostoma and Ceratocystis. Pages 117-125 in: Ceratocystis and Ophiostoma. Taxonomy, Ecology and Pathogenicity. M. J. Wingfield, K. A. Seifert, and J. F. Webber, eds. The American Phytopathological Society, St. Paul, MN.

21. Harrington, T. C., and McNew, D. L. 1997. Self-fertility and unidirectional mating-type switching in Ceratocystis coerulescens, a filamentous ascomycete. Curr. Genet. 32:52-59.
22. Harrington, T. C., and Wingfield, M. J. 1998. The Ceratocystis species on conifers. Can. J. Bot. 76:1446-1457.

23. Havard, J.-C. 2002. Add value to your lumber: Avoiding sapstain increasing saleability. Online publication. The Working Forest. Vol. 6 Issue 3.

24. Held, B. W., Thwaites, J. M., Farrell, R. L., and Blanchette, R. A. 2003. Albino strains of Ophiostoma species for biological control of sapstaining fungi. Holzforschung 57:237-242.

25. Kile, G. A. 1993. Plant diseases caused by species of Ceratocystis sensu stricto and chalara. Pages 173-183 in: Ceratocystis and Ophiostoma. Taxonomy, Ecology and Pathogenicity. M. J. Wingfield, K. A. Seifert, and J. F. Webber, eds. The American Phytopathological Society, St. Paul, $\mathrm{MN}$.

26. Klepzig, K. D. 1998. Competition between a biological control fungus, Ophiostoma piliferum, and symbionts of the southern pine beetle. Mycologia 90:69-75.

27. Morales, L., and Dickinson, D. J. D. 1998. A study of the factors governing the performance of preservatives used for the prevention of sapstain on seasoning wood with regard to the establishment of European standards: Overview of co-operative project and development of laboratory test methods. Pages 77-85 in: Biology and Prevention of Sapstain. Forest Products Society, Madison, WI.

28. Morin, C., Breuil, C., and Bernier, L. 2004. Genetic variability and structure of Canadian populations of the sapstain fungus Ceratocystis resinifera. Phytopathology 94:1323-1330.

29. Morrell, J. J., and Dawson-Andoh, B. E. 1998. Biological control: Panacea or boondoggle. Pages 39-44 in Biology and Prevention of Sapstain. Forest Products Society, Madison, WI.

30. Morrell, J. J., Love, C. S., and Freitag, C. M. 2002. Preventing discoloration of unseasoned hem-fir and Douglas-fir lumber with selected fungicide formulations. Forest Prod. J. 52:53-61.

31. Pest Management Regulatory Agency. Health Canada. 2004. Ophiostoma piliferum Strain D97, Sylvanex Technical (TGAI), Sylvanex (EP). Regulatory Note. REG2004-05.

32. Roff, J. W., Cserjesi, A. J., and Swann, H. W. 1974. Prevention of sapstain and mold in packaged lumber. Can. For. Serv. Publ. 1325.

33. Seifert, K. A. 1993. Sapstain of commercial lumber by species of Ophiostoma and Ceratocystis. Pages 141-151 in: Ceratocystis and Ophiostoma. Taxonomy, Ecology and Pathogenicity. M. J. Wingfield, K. A. Seifert, and J. F. Webber, eds. The American Phytopathological Society, St. Paul, $\mathrm{MN}$.

34. Tanguay, P., Loppnau, P., Morin, C., Bernier, L., and Breuil, C. 2006. A spontaneous albino mutant of Ceratocystis resinifera results from a point mutation in the polyketide synthase gene (PKS1). Can. J. Microbiol. (In press.)

35. Uzunovic, A., and Webber, J. F. 1998. Comparison of bluestain fungi grown in vitro and in freshly cut pine billets. Eur. J. For. Pathol. 28:323334.

36. Uzunovic, A., Webber, J. F., and Dickinson, D. J. 1998. Influence of bark damage on bluestain development in pine logs. Pages 23-28 in: Biology and Prevention of Sapstain. Forest Products Society, Madison, WI.

37. Uzunovic, A., Yang, D.-Q., Gagné, P., Breuil, C., Bernier, L., Byrne, A., Gignac, M., and Kim, S. H. 1999. Fungi that cause sapstain in Canadian softwoods. Can. J. Microbiol. 45:914-922.

38. White-McDougall, W. J., Blanchette, R. A., and Farrell, R. L. 1998. Biological control of blue stain fungi on Populus tremuloides using selected Ophiostoma isolates. Holzforschung 52:234-240.

39. Yang, D.-Q., Gagné, P., Uzonovic, A., Gignac, M., and Bernier, L. 1999. Development of fungal stain in logs of three Canadian softwoods. For. Prod. J. 49:39-42.

40. Zimmerman, W. C., Blanchette, R. A., Burnes, T. A., and Farrell, R. L. 1995. Melanin and perithecial development in Ophiostoma piliferum. Mycologia 87:857-863. 